\title{
Smokers' interest in a lung cancer screening programme: a national survey in England
}

Samantha L. Quaife ${ }^{1 *}$, Charlotte Vrinten ${ }^{1}$, Mamta Ruparel ${ }^{2}$, Samuel M. Janes ${ }^{2}$, Rebecca J. Beeken ${ }^{1,3}$, Jo Waller ${ }^{1}$ and Andy McEwen ${ }^{1}$

\begin{abstract}
Background: Following the recommendation of lung cancer screening in the US, screening committees in several European countries are reviewing the evidence for implementing national programmes. However, inadequate participation from high-risk groups poses a potential barrier to its effectiveness. The present study examined interest in a national lung cancer screening programme and modifiable attitudinal factors that may affect participation by smokers.

Methods: A population-based survey of English adults ( $n=1464$; aged 50-70 years) investigated screening intentions in different invitation scenarios, beliefs about lung cancer, early detection and treatment, worry about lung cancer risk, and stigma. Data on smoking status and perceived chances of quitting were also collected, but eligibility for lung screening in the event of a national programme was unknown.

Results: Intentions to be screened were high in all three invitation scenarios for both current $(\geq 89 \%)$ and former ( $\geq 94 \%$ ) smokers. However, smokers were less likely to agree that early-stage survival is good (43\% vs. 53\%; OR: 0.64, $0.46-0.88$ ) or be willing to have surgery for an early stage, screen-detected cancer (84\% vs. 94\%; OR: 0.38, 0.21-0.68), compared with former smokers. Willingness to have surgery was positively associated with screening intentions; with absolute differences of $25 \%$ and $29 \%$. Worry about lung cancer risk was also most common among smokers (48\%), and one fifth of respondents thought screening smokers was a waste of NHS money.

Conclusions: A national lung cancer screening programme would be well-received in principle. To improve smokers' participation, care should be taken to communicate the survival benefits of early-stage diagnosis, address concerns about surgery, and minimise anxiety and stigma related to lung cancer risk.
\end{abstract}

Keywords: Lung cancer screening, Early detection, Screening uptake, Smoking, Attitudes, Behavioural science

\section{Background}

Lung cancer is the leading cause of cancer mortality worldwide and typically has a bleak prognosis [1]; partly because early diagnoses are infrequent [2]. Low-dose computed tomography (LDCT) screening offers a means of detecting disease early, and was shown by the US National Lung Screening Trial (NLST) to reduce the relative risk of lung cancer mortality by $20 \%$, compared with chest X-ray, for high-risk adults screened annually over

\footnotetext{
* Correspondence: samantha.quaife@ucl.ac.uk

${ }^{1}$ Department of Behavioural Science and Health, University College London, Gower Street, London WC1E 6BT, UK

Full list of author information is available at the end of the article
}

3 years [3]. Screening is recommended by the US Preventive Services Task Force (USPSTF) for current smokers and recent ex-smokers $(\leq 15$ years since quitting) aged 55 to 80 , who have accrued a 30 pack-year smoking history [4], and is funded by Medicare and Medicaid [5]. Implementation in the UK is under review by the National Screening Committee [6].

Crucial to the effectiveness of lung cancer screening is uptake by those at high risk. This will optimise the riskbenefit ratio as the majority $(88 \%)$ of deaths prevented by the NLST were for participants scoring within the three highest risk quintiles [7]. However, enrolment into trials has been low, at less than $5 \%$ of all those invited in

(c) The Author(s). 2018 Open Access This article is distributed under the terms of the Creative Commons Attribution 4.0 International License (http://creativecommons.org/licenses/by/4.0/), which permits unrestricted use, distribution, and reproduction in any medium, provided you give appropriate credit to the original author(s) and the source, provide a link to the Creative Commons license, and indicate if changes were made. The Creative Commons Public Domain Dedication waiver (http://creativecommons.org/publicdomain/zero/1.0/) applies to the data made available in this article, unless otherwise stated. 
the target age range, and biased toward those at lower risk. Current smoking status and low socioeconomic position (SEP) have predicted lower attendance across European and US trials [8-10]; the very factors associated with increased risk [11].

Surveys carried out in the community find smokers are more likely to express negative attitudes towards screening. One US population survey $(n=2001)$ found that, compared with former smokers, fewer current smokers were willing to be screened, believed early detection can increase survival, or anticipated agreeing to surgery for a screen-detected cancer [12]. In a US survey of ethnic minority groups, concerns about survival, radiation, financial cost, and the CT scan process predicted lower screening intentions [13]. More recently, an online US survey found that high perceived risk, low fear of CT scans and confidence in their accuracy, and the belief that early detection can improve prognosis, together predicted agreement to a LDCT scan [14]. In the UK, a mixed methods study of lower SEP communities suggested that fatalism about survival, risk, and treatment, and fear of an expected diagnosis may constitute important psychosocial deterrents for smokers [15]. Studies of trial non-participants have also implicated psychological deterrents, including emotional barriers such as fear, worry and avoidance [16, 17], fatalistic views and perceptions of low benefit in older age [18], and a lack of awareness that screening is beneficial for asymptomatic individuals [18]. Added to this is the potential role of social factors such as perceived stigmatisation of smoking $[15,19]$.

Characteristics of the invitation could also affect screening uptake. UK screening programmes for breast, colorectal and cervical cancer organise invitations through central NHS hubs, but there is good evidence that GP endorsement [20] and pre-scheduled appointments [21] improve uptake. The acceptability of these different invitation scenarios has not been studied for lung cancer screening.

This study aimed to: i) examine how screening intentions and perceptions of early detection of lung cancer might differ by smoking status, and ii) measure interest in, and acceptability of, an NHS lung cancer screening programme offered in different invitation scenarios.

\section{Methods}

A population-based sample of adults aged $50-70$ years took part in the Attitudes, Behaviour and Cancer UK Survey (ABACUS) in April 2015. This age group was selected to represent individuals who could be eligible for, or approaching eligibility for, lung cancer screening according to the USPSTF criteria [4]. The survey was administered within the rolling Omnibus survey [22] carried out by TNS Research International, which uses home-based computer-assisted, face-to-face interviews. Sampling points in England were selected using stratified random location sampling from the 2011 Census small area statistics [23], the Postcode Address File and Government Office Regions. At each sampling location, quotas were set for age, gender, children residing in the household, and employment status.

\section{Measures}

A brief, standardised description of lung cancer screening was provided and single-item questions were adapted from existing measures and studies, and piloted in cognitive interviews $(n=15)$, and an online survey ( $n$ $=391$ ) prior to this study.

\section{Lung cancer screening intentions}

Participants were asked to rate their intention to be screened following three hypothetical invitation scenarios presented in the same order to all participants: i) an invitation from a national NHS programme, ii) a GP recommendation, and iii) an upcoming pre-scheduled appointment next month. These items were adapted from the colorectal cancer screening literature [24]. It was made clear to participants that there is currently no national lung cancer screening programme in England. Responses were on a five-point scale for the first two items ('yes definitely', 'yes probably', 'probably not', 'definitely not,' 'not sure') and the third item ('very likely,' 'likely,' 'unlikely', 'very unlikely', 'not sure'). They were dichotomised for analysis as 'yes definitely/probably' vs. 'probably/definitely not', and 'very likely/likely' vs. 'very unlikely/unlikely'. Those answering 'not sure' or 'refused' on any of the three items were excluded.

\section{Beliefs about lung cancer survival, early detection and screening}

Two items were taken from the Awareness and Beliefs about Cancer $(\mathrm{ABC})$ measure [25] concerning survival from cancer and lung cancer ('a diagnosis of cancer/lung cancer is a death sentence'). Response options were on a four-point scale dichotomised as 'strongly/tend to agree' vs. 'strongly/tend to disagree' for analysis. Participants could answer 'don't know' or 'refused', but these responses were excluded from analyses. Participants who had been diagnosed with cancer $(n=127)$ were not asked these questions.

Two items were adapted from Silvestri and colleagues' US survey [12] to assess beliefs about early-stage lung cancer: 'If lung cancer is detected early, what is the person's chance of surviving?' (response options on a threepoint scale, dichotomised for analysis as 'good' vs. 'fair/ poor') and 'If the screening test found that you had early-stage lung cancer, would you want to have the recommended surgery?' (responses were coded as 'yes 
definitely/probably' or 'probably/definitely not'). 'Not sure,' don't know' or 'refused' responses were excluded.

The acceptability of a screening programme was also assessed ('Do you think lung cancer screening is a good idea?'), as well as opposition against screening targeted at smokers as an indicator of stigma ('Do you think that offering lung cancer screening to smokers is a waste of NHS money?') adapted from a validated cancer stigma scale [26]. Response options were 'yes' or 'no'; 'don't know' or 'refused' responses were excluded.

\section{Worry about lung cancer risk}

Frequency of worry about lung cancer risk was measured by asking, 'How often do you worry about your chance of getting lung cancer?'; adapted from Lerman's Cancer Worry Scale [27, 28]. Response options were 'never,' 'occasionally', 'sometimes', 'often', 'very often', which were recoded as 'never' vs. 'at least occasionally' for analysis. Respondents who reported worry were asked, 'Would a clear lung CT scan reassure you?', to which they could respond 'yes' or 'no'. 'Don't know' and 'refused' responses were excluded from analyses.

\section{Smoking}

Smoking status was self-reported using the following two items from the ABC measure [25]. First, 'Do you smoke at all these days, either cigarettes (including hand-rolled ones), pipes or cigars?' and second, 'Have you ever regularly smoked cigarettes (including handrolled ones), pipes or cigars?'. Former smokers were therefore defined as individuals who had ever smoked tobacco regularly. We did not collect data on tobacco consumption or smoking duration and therefore could not determine likely screening eligibility status.

Current smokers were asked, 'How high would you rate your chances of giving up smoking for good?' on a scale adapted from the 'Motivation To Stop Scale' (MTSS) [29]. Responses were dichotomised as high ('extremely', 'very high', 'quite high') vs. low ('not very high', 'low' or 'very low') for analysis.

\section{Demographics}

Data on age, gender, ethnicity (White/Not White), marital status (i) married/cohabiting, ii) single/divorced/separated/widowed), and highest level of education (i) no formal qualifications, ii) CSEs/Olevels/equivalent, iii) A-levels/further education/ equivalent, iv) Degree or higher) were collected. Cancer experience was assessed: 'Have any friends or family members that are close to you ever been diagnosed with cancer?' to which participants could answer 'yes' or 'no'.

\section{Analyses}

Descriptive frequencies were run to determine absolute levels of agreement. The associations between smoking status and agreement with each cancer belief and worry item were explored using chi-square analyses, and multivariable logistic regression, adjusted for demographics and cancer experience. 'Don't know' $(\leq 6.9 \%)$ and 'refused' $(\leq 4.9 \%)$ responses were excluded from the respective analyses.

Chi-square and logistic regression analyses were also carried out to test for associations between demographics, smoking status, and screening intentions. Belief items associated with smoking status were then analysed to determine their association with screening intentions. Analyses of screening intentions excluded never smokers because they would not be eligible for lung cancer screening. Analyses also excluded cases answering 'not sure' $(\leq 2.5 \%)$ or 'refused' $(\leq 2.3 \%)$ on any one of the three intention items $(n=44)$. Further analyses tested for demographic differences between this group and the overall sample.

Finally, exploratory chi-square and logistic regression analyses tested for associations between quit confidence and the beliefs, lung cancer worry and screening intention variables among current smokers only. As multiple testing increases the type one error rate, a stringent significance threshold was set for the interpretation of all analyses $(p<.01)$.

\section{Results}

\section{Sample characteristics}

In total, 1464 participants completed the survey. Participants were excluded if they did not report their smoking status $(n=13)$ or had been diagnosed with lung cancer $(n=6)$. The average age of the final sample was 60 years and there was good representation of different SEP (as indicated by education level; see Table 1 ). The majority were married or cohabiting (62\%), and from a White ethnic background (93\%). Experience of cancer through friends or family was commonly reported (70\%).

Twenty two per cent of participants were current smokers, $26 \%$ were former smokers and $52 \%$ reported never having smoked. Current smokers had a lower level of education, and were less likely to be married (p's $<.001)$. Most smokers (62\%) rated their chances of stopping smoking as 'very low', 'low' or 'not very high'. Beyond age and smoking status, participants' likely eligibility in the event of a national lung cancer screening programme was unknown.

Compared with the main sample, current and former smokers answering 'don't know' or 'refused' on the intention items $(n=44$; excluded from the intention analyses) did not differ in their sociodemographic characteristics. 
Table 1 Characteristics of the sample by smoking status

\begin{tabular}{|c|c|c|c|c|}
\hline & All $(n=1445)$ & Never smokers $(n=759)$ & Current smokers $(n=313)$ & Former smokers $(n=373)$ \\
\hline \multicolumn{5}{|l|}{ Gender, \% (n) } \\
\hline Male & $49.3(712)$ & $44.0(334)^{\mathrm{b}}$ & $55.9(175)^{\mathrm{b}}$ & $54.4(203)^{b}$ \\
\hline Female & $50.7(733)$ & $56.0(425)$ & $44.1(138)$ & $45.6(170)$ \\
\hline Age, mean (SD) & $60.4(6.3)$ & $60.1(6.3)$ & $59.2(6.3)$ & $61.8(6.1)$ \\
\hline \multicolumn{5}{|l|}{ Marital status, \% (n) } \\
\hline Married/Cohabiting & $61.7(892)$ & $65.3(496)^{b}$ & $48.2(151)^{b}$ & $65.7(245)^{\mathrm{b}}$ \\
\hline Single/Divorced/Separated/Widowed & $38.3(553)$ & $34.7(263)$ & $51.8(162)$ & $34.3(128)$ \\
\hline \multicolumn{5}{|l|}{ Ethnicity, \% (n) } \\
\hline White & $92.9(1342)$ & $89.3(678)^{b}$ & $95.5(299)^{\mathrm{b}}$ & $97.9(365)^{\mathrm{b}}$ \\
\hline Not White & $6.9(100)$ & $10.4(79)$ & $4.5(14)$ & $1.9(7)$ \\
\hline Refused & $0.2(3)$ & $0.3(2)$ & $0.0(0)$ & $0.3(1)$ \\
\hline \multicolumn{5}{|l|}{ Education level, \% (n) } \\
\hline Degree & $20.2(292)$ & $26.2(199)^{\mathrm{b}}$ & $10.2(32)^{b}$ & $16.4(61)^{b}$ \\
\hline A-levels/further/equivalent & $22.6(327)$ & $24.0(182)$ & $16.9(53)$ & $24.7(92)$ \\
\hline CSEs/O-levels/equivalent & $28.3(409)$ & $26.0(197)$ & $33.5(105)$ & $28.7(107)$ \\
\hline No formal qualifications & $26.1(377)$ & $21.2(161)$ & $36.4(114)$ & $27.3(102)$ \\
\hline Don't know/Refused & $2.8(40)$ & $2.6(20)$ & $2.9(9)$ & $2.9(11)$ \\
\hline \multicolumn{5}{|l|}{ Cancer experience, \% (n) } \\
\hline Yes (friends/family) & $70.2(1014)$ & $68.8(522)$ & $69.0(216)$ & $74.0(276)$ \\
\hline No & $28.2(407)$ & $30.0(228)$ & $29.1(91)$ & $23.6(88)$ \\
\hline Don't know/Refused & $1.7(35)$ & $1.2(9)$ & $1.9(6)$ & $2.4(9)$ \\
\hline \multicolumn{5}{|l|}{ Quit confidence, \% (n) } \\
\hline Extremely high & - & - & $4.2(13)$ & - \\
\hline Very high & - & - & $10.2(32)$ & - \\
\hline Quite high & - & - & $20.1(63)$ & - \\
\hline Not very high & - & - & $21.7(68)$ & - \\
\hline Low & - & - & $13.7(43)$ & - \\
\hline Very low & - & - & $26.2(82)$ & - \\
\hline Don't know/Refused & - & - & $3.8(12)$ & - \\
\hline
\end{tabular}

$\%$ totals may not be exactly 100 due to rounding

${ }^{\mathrm{a}} \mathrm{X}^{2}, p<.01,{ }^{\mathrm{b}} \mathrm{X}^{2}, p<.001$

\section{Beliefs about lung cancer survival, early detection and screening}

One in five respondents agreed that a cancer diagnosis is a death sentence, but this number doubled (48\%) when the question concerned lung cancer (see Table 2). In relation to early-stage lung cancer, only half thought the chances of surviving were good, but $92 \%$ anticipated they would opt for surgery. Smokers were less likely to agree with these beliefs compared with former smokers (43\% vs. $53 \%, p=.01$; OR: $0.64,0.46-0.88$, and $84 \%$ vs. $94 \%, p<.001$; OR: 0 . $38,0.21-0.68$ respectively).

The large majority of participants (97\%) thought screening a good idea, across smoking groups. Using NHS money to screen smokers was perceived as a waste of NHS money by
$21 \%$, but most commonly by former (24\%) and never smokers (22\%) compared with current smokers (14\%; OR: 0. 45, 0.29-0.69; reference group was former smokers).

While there was a trend towards smokers with a lower perceived chance of stopping smoking endorsing more negative beliefs, there were no statistically significant associations in unadjusted analyses $(n=301$; see Table 3$)$. In adjusted analyses, smokers who perceived their chance of quitting as low were less likely to agree that early stage survival is good compared with those rating their chance of quitting as high (37\% vs. $52 \%, p=.02$; OR: 0.48, 0.29-0.82).

\section{Worry about lung cancer risk}

Worrying about risk of lung cancer at least occasionally was fairly common overall (31\%; see Table 2 ). More 
Table 2 Frequencies, chi-square analyses and multivariable logistic regression models ${ }^{c}$, testing the associations between smoking status, beliefs and worry

\begin{tabular}{|c|c|c|c|c|c|c|c|c|c|}
\hline & \multirow{2}{*}{$\begin{array}{l}\text { All }(n=1445) \\
\%(n)\end{array}$} & \multicolumn{2}{|c|}{$\begin{array}{l}\text { Former smokers } \\
\text { (reference) }\end{array}$} & \multicolumn{3}{|c|}{ Current smokers } & \multicolumn{3}{|c|}{ Never smokers } \\
\hline & & $\%(n)$ & $\mathrm{OR}$ & $\%(\mathrm{n})$ & OR & $95 \% \mathrm{Cl}$ & $\%(n)$ & OR & $95 \% \mathrm{Cl}$ \\
\hline \multicolumn{10}{|l|}{ A diagnosis of cancer is a death sentence } \\
\hline Strongly/tend to agree (vs. strongly/tend to disagree) & $20.5(257)$ & $16.9^{\mathrm{a}}(53)$ & 1.00 & $26.8^{\mathrm{a}}(75)$ & 1.50 & $0.97-2.29$ & $19.6^{\mathrm{a}}(129)$ & 1.29 & $0.88-1.90$ \\
\hline \multicolumn{10}{|l|}{ A diagnosis of lung cancer is a death sentence } \\
\hline Strongly/tend to agree (vs. strongly/tend to disagree) & $47.6(582)$ & $46.3(138)$ & 1.00 & $53.2(149)$ & 1.25 & $0.89-1.76$ & $45.7(295)$ & 1.01 & $0.76-1.35$ \\
\hline \multicolumn{10}{|l|}{$\begin{array}{l}\text { If lung cancer is detected early, what is the person's chance } \\
\text { of surviving? }\end{array}$} \\
\hline Good (vs. fair/poor) & $50.8(689)$ & $53.4(189)$ & 1.00 & $43.0(125)$ & 0.64 & $0.46-0.88$ & $52.7(375)$ & 0.95 & $0.73-1.24$ \\
\hline \multicolumn{10}{|l|}{$\begin{array}{l}\text { If the screening test found that you had early-stage lung } \\
\text { cancer, would you want to have the recommended surgery? }\end{array}$} \\
\hline Yes definitely/probably (vs. definitely/probably not) & $91.5(1209)$ & $93.9^{\mathrm{b}}(321)$ & 1.00 & $84.3^{\mathrm{b}}(242)$ & 0.38 & $0.21-0.68$ & $93.4^{\mathrm{b}}(646)$ & 0.99 & $0.56-1.75$ \\
\hline \multicolumn{10}{|l|}{ Do you think that lung cancer screening is a good idea? } \\
\hline Yes (vs. no) & $97.1(1354)$ & $97.8(352)$ & 1.00 & $96.7(294)$ & 0.67 & $0.25-1.77$ & $97.0(708)$ & 1.10 & $0.46-2.63$ \\
\hline \multicolumn{10}{|l|}{$\begin{array}{l}\text { Do you think that offering screening to smokers is a } \\
\text { waste of NHS money? }\end{array}$} \\
\hline Yes (vs. no) & $20.7(281)$ & $23.9^{\mathrm{a}}(84)$ & 1.00 & $14.2^{\mathrm{a}}(43)$ & 0.45 & $0.29-0.69$ & $21.9^{\mathrm{a}}(154)$ & 0.92 & $0.67-1.27$ \\
\hline \multicolumn{10}{|l|}{$\begin{array}{l}\text { How often do you worry about your chance of getting } \\
\text { lung cancer? }\end{array}$} \\
\hline Very often to occasionally (vs. never) & $30.6(429)$ & $28.7^{\mathrm{b}}(104)$ & 1.00 & $47.9^{\mathrm{b}}(147)$ & 2.38 & $1.70-3.33$ & $24.4^{\mathrm{b}}(178)$ & 0.81 & $0.60-1.10$ \\
\hline \multicolumn{10}{|l|}{ Would a clear CT scan reassure you? } \\
\hline Yes (vs. no) & $90.0(385)$ & $94.2(97)$ & 1.00 & $89.7(130)$ & 0.66 & $0.24-1.84$ & $87.8(158)$ & 0.75 & $0.27-2.05$ \\
\hline
\end{tabular}

OR odds ratio, $95 \% \mathrm{Cl} 95 \%$ confidence interval; $\mathrm{n}$ totals may not sum due to missing data

${ }^{\mathrm{a}} \mathrm{X}^{2}, p<.01,{ }^{\mathrm{b}} \mathrm{X}^{2}, p<.001$

cadjusted for demographics and cancer experience

dasked of the subsample of participants reporting lung cancer worry $(n=429)$

current smokers reported this worry (48\%), compared with former smokers (29\%; OR: 2.38, 1.70-3.33), and fewer never smokers compared with former smokers ( $24 \%$ vs. $29 \%, p<.001)$; although the latter association was not statistically significant in adjusted analyses (OR: $0.81,0.60-1.10)$. Of the participants who worried about their risk $(n=429), 90 \%$ thought a clear CT scan would be reassuring, with no association with smoking status.

\section{Lung cancer screening intentions}

The large majority of current and former smokers intended to be screened for lung cancer (see Table 4). The proportion of intenders was highest if recommended by a GP $(93 \%$ and $98 \%$, for current and former smokers respectively), and was similar for the NHS (89\% and $94 \%$ for current and former smokers) and upcoming appointment (89\% and 94\%) invitation scenarios.

Gender, age, ethnicity, level of education, marital status and cancer experience were not associated with screening intentions. Smoking status was associated with screening intentions in the GP invitation scenario only. Fewer current smokers (93\%) than former (98\%) smokers intended to participate following a GP recommendation $(p<.01$; OR: 0.24, 0.09-0.65). Smokers' perceived chance of quitting smoking was not associated with their intentions to be screened.

Perceived survival from early-stage lung cancer was associated with screening intentions in the GP invitation scenario (see Table 4), with decreased odds for those thinking survival was poor or fair $(94 \%)$, compared with good $(98 \%, p<.01$; OR: $0.23,0.08-0.71)$. Anticipating not wanting surgery for a screendetected early-stage lung cancer predicted a lower likelihood of intending to be screened in all three scenarios. Striking absolute differences in intentions were observed between the 'decline' and 'pro' surgery participants $(26-29 \%$; ORs: $0.04-0.14, p<.001)$.

Worrying about risk of lung cancer did not affect the odds of intending to be screened in any of the invitation scenarios. However, this group was predominantly comprised of individuals who worried sometimes or occasionally (85\% of the current and former smokers reporting worry and included in the screening intention analyses).

There were too few cases to subdivide the frequency of worry by screening intentions for multivariate analysis. 
Table 3 Frequencies, chi-square analyses, and multivariable logistic regression models ${ }^{\mathrm{a}}$, exploring associations between smokers' perceived chance of quitting, lung cancer beliefs and screening intentions

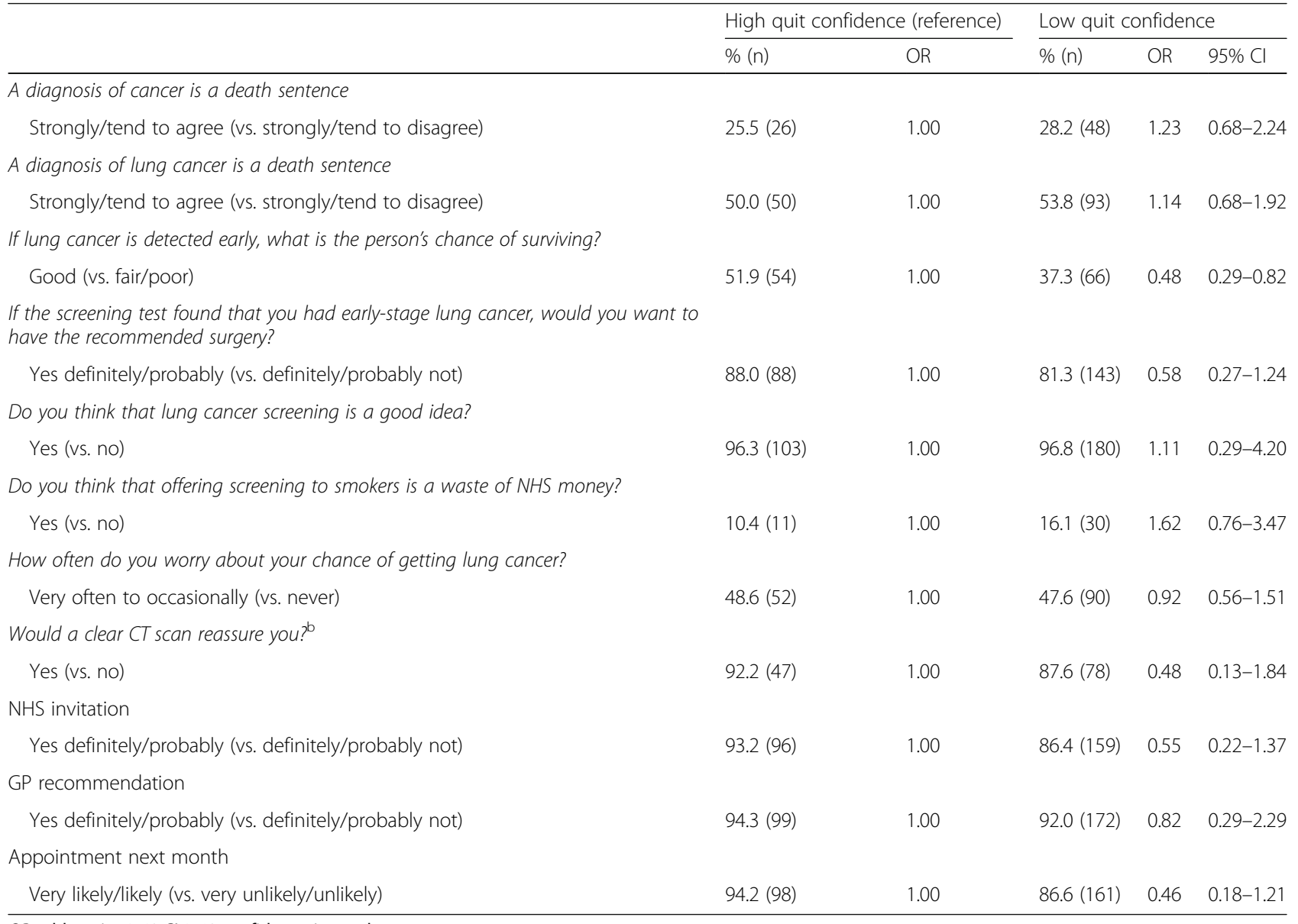

OR odds ratio; $95 \%$ Cl 95\% confidence interval

adjusted for demographics and cancer experience

basked of the subsample of participants reporting lung cancer worry $(n=142)$

The results of unadjusted Fisher's exact tests suggested that infrequent worry (i.e. occasionally or sometimes) was associated with higher screening intentions, whereas frequent worry (i.e. often or very often) was associated with lower intentions in the NHS invitation scenario $(p=.01$; results not reported).

\section{Discussion}

This is the first UK population-based study of older adults to investigate interest in, and perceptions of lung cancer screening, and to explore their association with smoking status. Most respondents thought screening a good idea and the majority of current and former smokers intended to be screened. However, positive intentions were at odds with frequently fatalistic perceptions of lung cancer. Negative beliefs about early-stage survival and surgery were particularly common among smokers, and associated with a lower likelihood of intending to be screened.
Based on intentions alone, these findings suggest that a UK national screening programme would be acceptable and well-attended; perhaps especially if recommended by a GP. These findings match the interest observed among a US population-based survey [12]. However, they are contrary to the low levels of screening uptake observed in the trial context [10]. The gap between intentions and behaviour is well-documented for health precautionary behaviours [30] suggesting these intentions may not be borne out in attendance. Cognitive, psychosocial or practical factors may subsequently determine whether intentions are enacted.

Beliefs about the screened disease could be an important factor. Perceptions of survival from lung cancer were frequently negative; even when early detection was specified. This is likely to reflect the poor prognosis lung cancer currently has, due largely to its late diagnosis. A deep-rooted lay interpretation might be that outcomes are universally poor, and there is evidence that earlystage survival is underestimated [31]. Notably, smokers 
Table 4 Frequencies, chi-square analyses, and multivariable logistic regression models ${ }^{c}$, exploring associations with lung cancer screening intentions among current and former smokers

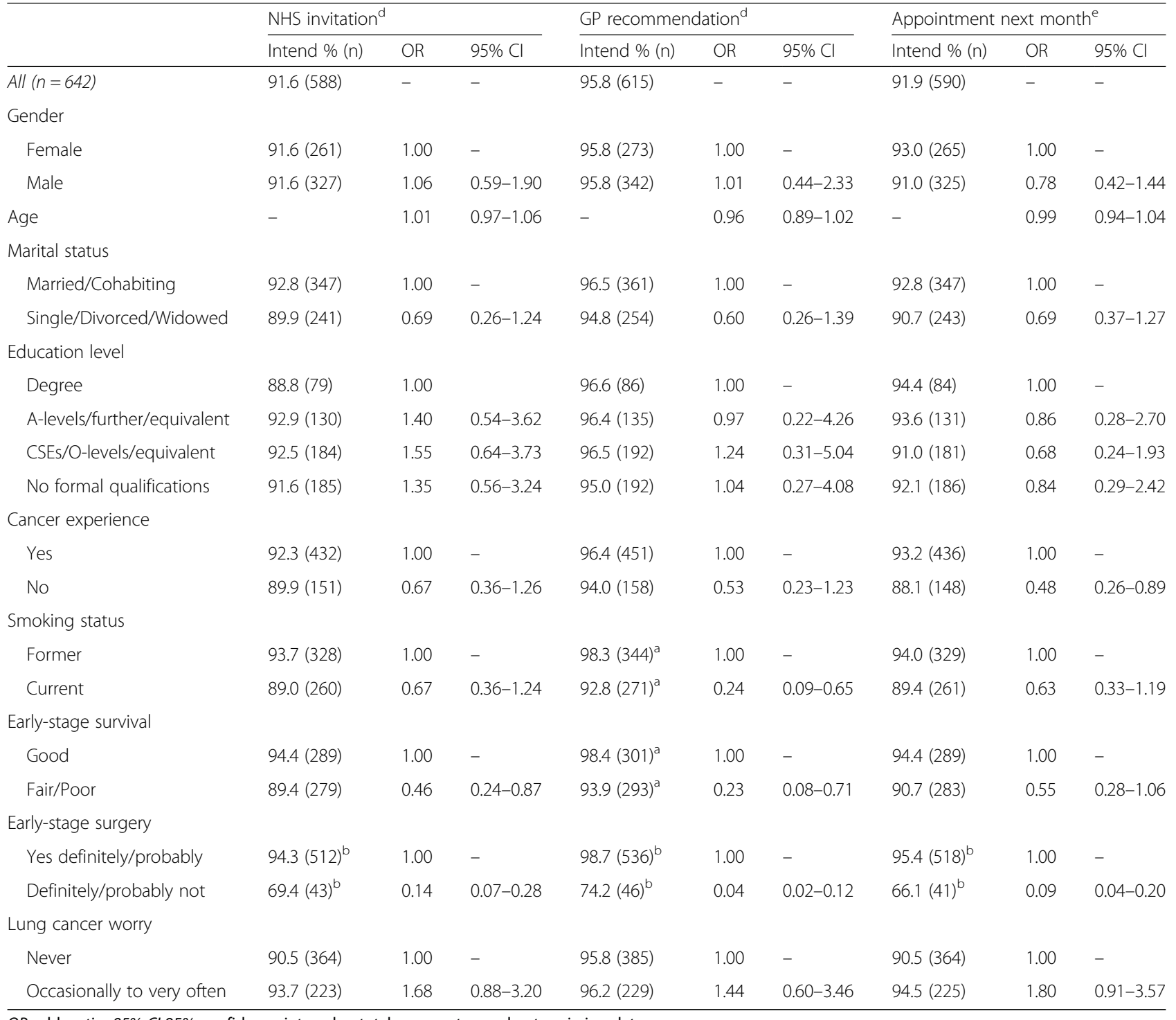

OR odds ratio; $95 \% \mathrm{Cl}$ 95\% confidence interval; $\mathrm{n}$ totals may not sum due to missing data

${ }^{\mathrm{a}} \mathrm{X}^{2}, p<.01 ;{ }^{\mathrm{b}} \mathrm{X}^{2}, p<.001$

cadjusted for demographics, cancer experience and smoking status

dpredicting yes definitely/probably vs. probably/definitely not

epredicting very likely/likely vs. very unlikely/unlikely

were the most negative. Fewer believed there is a good chance of surviving early-stage lung cancer, or that they would undergo surgery for a screen-detected cancer, mirroring the results of the US survey [12]. Smokers in this UK sample were more accepting of surgical treatment ( $84 \%$ vs. $56 \%$ ), which could partly be due to differences in healthcare provision, as US smokers were more likely to be deterred by cost. Importantly, those holding negative beliefs about early-stage survival and surgery were less likely to intend to be screened, suggesting that negative perceptions of early detection could undermine smokers' screening intentions.
Smokers' greater pessimism about early-stage lung cancer may result from more negative experiences of the disease within their social networks. We adjusted for previous cancer experience, but did not assess the type. Alternatively, perhaps smokers in this relatively older age group have become increasingly fatalistic about their chances of surviving lung cancer because of their significant smoking history, such that screening and treatment are perceived as offering little promise. These feelings may be exacerbated by their tobacco dependence, especially if they feel unable to quit; important because a sizeable proportion of smokers $(>60 \%)$ rated their chances of quitting 
as low. While perceived chance of quitting was not associated with screening intention, this study provided preliminary evidence that lower perceptions of quitting could foster more negative perceptions of early detection for lung cancer. This hypothesis deserves further study.

Worry about risk of lung cancer was most prevalent among smokers; nearly half reported worrying at least occasionally. Overall, worry did not appear to affect the likelihood of intending to be screened among current and former smokers. However, subgroup analyses showed that frequent worriers actually had lower intentions to be screened, and that infrequent worriers had the highest intentions in the NHS invitation scenario. Although preliminary, these results are consistent with evidence for a curvilinear association [32]. Studies are needed to measure the constituent components of smokers' worry, including frequency, and to explore their effects on screening participation.

While many respondents worried about their risk of lung cancer, most believed they would find a clear screen reassuring. However, this belief may be irrelevant if screening is expected to lead to a lung cancer diagnosis, and smokers may therefore be less likely to anticipate reassurance. Previous data have shown smokers are more likely to delay symptomatic help-seeking [33] due to worry about what the doctor might find [34]. Studies have also warned that lung cancer screening could undermine motivation to stop smoking [35]. However, with the correct communication, screening offers the opportunity to both assist smoking cessation and raise symptom awareness. Research is needed which explores the psychological responses to different screening results to identify how best to communicate lung cancer risk to assist positive behaviour change.

Lung cancer screening would be the first cancer screening programme in the UK to select patients primarily using a behavioural risk factor. In this sample, nearly one fifth thought screening smokers would be a waste of NHS money, suggesting that the stigma attached to smoking may adversely affect the acceptability of a targeted programme. This finding also warns that the exclusion of never smokers could be a contentious issue as they can also develop lung cancer, and a quarter of never smokers reported worrying about this. Opposition to their exclusion should be addressed by carefully communicating why LDCT screening is only appropriate for those at high risk.

This study benefits from a large, population-based sample, with a higher proportion of smokers (22\%) than was expected for this age group [36] and good representation of different SEP groups. The measurement of screening intentions was useful for exploring interest, but limited conclusions can be made about screening behaviour, because the two are not well-correlated [30].
This may have been exacerbated by the fact that the screening offer was hypothetical and social desirability bias may have inflated results. Furthermore, asking participants about multiple invitation scenarios may have led them to alter their response for subsequent scenarios relative to the previous scenarios. This method could have resulted in different invitation preferences compared to asking independent groups about each invitation scenario; although respondents could not alter their previous responses when interviewed. Alternative individual-level measures of SEP exist but education has been shown to be a good indicator in older samples [37]. Single-item, cross-sectional measures were chosen to minimise participant burden, but may have reduced the reliability of findings. For the same reason, we did not collect information on participants' smoking duration or history (i.e. pack years) which would have allowed us to determine their eligibility for lung cancer screening. We caution that not knowing the likely eligibility status of participants in our sample may reduce the generalisability of these findings to an eligible screening population in England, should a national screening programme be recommended.

\section{Conclusions}

The introduction of an NHS lung cancer screening programme appears to be acceptable to older UK adults, with most current and former smokers intending to be screened (upwards of $89 \%$ and $94 \%$, respectively) especially if recommended by their GP. Smokers' greater pessimism about survival and treatment for early-stage cancer could help to explain their lower participation. Strategies aimed at engaging smokers with screening should focus on improving perceptions of the curability of early-stage disease and addressing concerns about surgical treatment. Communication throughout the screening process needs to be sensitively devised so that it is mindful of the existing stigma around smoking, and the anxiety smokers may have about their increased risk of lung cancer.

\section{Abbreviations \\ ABACUS: Attitudes behaviour and cancer UK survey; ABC: Awareness and beliefs about cancer measure; GP: General practitioner; LDCT: Low-dose computed tomography; MTSS: Motivation to stop scale; NHS: National health service; SEP: Socioeconomic position; USPSTF: United States preventive services task force}

\section{Acknowledgements}

The authors would like to acknowledge the substantial intellectual contribution made by Professor Jane Wardle who sadly passed away prior to publication, and is deeply missed by all of her co-authors, colleagues and students.

\section{Funding}

CV, JW and AM are funded by Cancer Research UK. The Attitudes, Behaviour and Cancer UK Survey (ABACUS) was funded by a Cancer Research UK programme grant (C1418/A14134). SLQ was funded by the Medical Research 
Council (MR/K501268/1). RJB is supported by Yorkshire Cancer Research University Academic Fellowship funding. MR is funded by the Roy Castle Lung Cancer Foundation and a National Awareness and Early Diagnosis Initiative (NAEDI) project grant awarded by Cancer Research UK and a consortium of funders (Department of Health (England); Economic and Social Research Council; Health and Social Care R\&D Division, Public Health Agency, Northern Ireland; National Institute for Social Care and Health Research, Wales; Scottish Government). SMJ is a Wellcome Trust Senior Fellow in Clinical Science and is supported by Rosetrees Trust, the Welton Trust, the Garfield Weston Trust and UCLH Charitable Foundation. This work was partially undertaken at UCLH/UCL who received a proportion of funding from the Department of Health's NIHR Biomedical Research Centre's funding scheme (SMJ). SMJ is funded by the Roy Castle Lung Cancer Foundation and is part of the CRUK Lung Cancer Centre of Excellence.

\section{Availability of data and materials}

The datasets generated and analysed during the current study are not publically available due to ongoing analyses but are held at University College London, and available from the corresponding author on reasonable request (samantha.quaife@ucl.ac.uk).

\section{Authors' contributions}

SLQ, CV, RJB, JW and AM contributed to the design of the study and measures, statistical analysis, data interpretation and writing of the manuscript. MR and SJ contributed to the interpretation of the data and writing of the manuscript. All authors read and approved the final manuscript.

\section{Ethics approval and consent to participate}

This study was exempt from ethical approval by the UCL Research Ethics Committee because it used anonymous and non-sensitive survey methods with participants who did not comprise a vulnerable group.

\section{Competing interests}

SLQ, CV, MR, SMJ, RJB and JW have no competing interests to declare. AM has received travel funding, honorariums and consultancy payments from manufacturers of smoking cessation products (Pfizer Ltd., Novartis UK and GSK Consumer Healthcare Ltd) and hospitality from North51 who provide online and database services. AM also receives payment for providing training to smoking cessation specialists; receives royalties from books on smoking cessation and has a share in a patent of a nicotine delivery device AM is an Associate of the New Nicotine Alliance (NNA) that works to foster greater understanding of safer nicotine products and technologies.

\section{Publisher's Note}

Springer Nature remains neutral with regard to jurisdictional claims in published maps and institutional affiliations.

\section{Author details}

'Department of Behavioural Science and Health, University College London, Gower Street, London WC1E 6BT, UK. '2Lungs for Living Research Centre, UCL Respiratory, Division of Medicine, Rayne Building, University College London, 5 University Street, London WC1E 6JF, UK. ${ }^{3}$ Leeds Institute of Health Sciences, University of Leeds, Worsley Building, Clarendon Way, Leeds LS2 9NL, UK.

\section{Received: 23 March 2017 Accepted: 24 April 2018}

\section{Published online: 02 May 2018}

\section{References}

1. Office for National Statistics. Statistical Bulletin Cancer Survival in England: Adults Diagnosed, 2008 to 2012, followed up to 2013. 2014. https://www. ons.gov.uk/peoplepopulationandcommunity/healthandsocialcare/ conditionsanddiseases/bulletins/cancersurvivalinenglandadultsdiagnosed/ 2014-10-30. Accessed 13 Sept 2016

2. Eastern Cancer Registration and Information Centre. Stage distribution of cancers diagnosed in 2009 in the East of England by cancer site and area of residence. 2009. http://www.ecric.nhs.uk/docs/ECRIC_incidenceXstage_2009. pdf. Accessed 13 Sept 2016.

3. National Lung Screening Trial Research Team, Aberle DR, Adams AM, Berg CD, Black WC, Clapp JD, Fagerstrom RM, Gareen IF, Gatsonis C, Marcus PM,
Sicks JD. Reduced lung-cancer mortality with low-dose computed tomographic screening. N Engl J Med. 2011;365:395-409.

4. Moyer VA. Screening for lung cancer: U.S. preventive services task force recommendation statement. Ann Intern Med. 2014;160:330-8.

5. Centers for Medicare \& Medicaid services. Decision memo for screening for lung cancer with low dose computed tomography (LDCT) (CAG-00439N). 2015. https://www.cms.gov/medicare-coverage-database/details/ncadecision-memo.aspx?NCAld=274. Accessed 13 Sept 2016.

6. UK National Screening Committee. The UK NSC recommendation on lung cancer screening in adult cigarette smokers. 2016. http://legacy.screening. nhs.uk/lungcancer. Accessed 13 Sept 2016.

7. Kovalchik SA, Tammemagi M, Berg CD, Caporaso NE, Riley TL, Korch M, Silvestri GA, Chaturvedi AK, Katki HA. Targeting of low-dose CT screening according to the risk of lung-cancer death. N Engl J Med. 2013;369:245-54.

8. National Lung Screening Trial Research Team, Aberle DR, Adams AM, Berg CD, Clapp JD, Clingan KL, Gareen IF, Lynch DA, Marcus PM, Pinsky PF. Baseline characteristics of participants in the randomized national lung screening trial. J Natl Cancer Inst. 2010;102:1771-9.

9. Hestbech MS, Siersma V, Dirksen A, Pedersen JH, Brodersen J. Participation bias in a randomised trial of screening for lung cancer. Lung Cancer. 2011;73:325-31.

10. McRonald FE, Yadegarfar G, Baldwin DR, Devaraj A, Brain KE, Eisen T, Holemans JA, Ledson M, Screaton N, Rintoul RC, Hands CJ, Lifford K, Whynes D, Kerr KM, Page R, Parmar M, Wald N, Weller D, Williamson PR, Myles J, Hansell DM, Duffy SW, Field JK. The UK lung screen (UKLS): demographic profile of first 88,897 approaches provides recommendations for population screening. Cancer Prev Res. 2014;7:362-71.

11. Parkin DM. 2. Tobacco-attributable cancer burden in the UK in 2010. Br J Cancer. 2011;105 Suppl 2: S6-S13,.

12. Silvestri GA, Nietert PJ, Zoller J, Carter C, Bradford D. Attitudes towards screening for lung cancer among smokers and their non-smoking counterparts. Thorax. 2007;62:126-30.

13. Jonnalagadda S, Bergamo C, Lin JJ, Lurslurchachai L, Diefenbach M, Smith C, Nelson JE, Wisnivesky JP. Beliefs and attitudes about lung cancer screening among smokers. Lung Cancer. 2012;77:526-31.

14. Cataldo JK. High-risk older smokers' perceptions, attitudes, and beliefs about lung cancer screening. Cancer Med. 2016;5:753-9.

15. Quaife SL, Marlow LAV, McEwen A, Janes SM, Wardle J. Attitudes towards lung cancer screening within socioeconomically deprived and heavy smoking communities: informing screening communication. Health Expect. 2016;384:1-11.

16. Patel D, Akporobaro A, Chinyanganya N, Hackshaw A, Seale C, Spiro SG, Griffiths C. Attitudes to participation in a lung cancer screening trial: a qualitative study. Thorax. 2012;67:418-25.

17. Ali N, Lifford K, Carter B, McRonald F, Yadegarfar G, Baldwin DR, Weller D, Hansell DM, Duffy SW, Field JK, Brain K. Barriers to uptake among high-risk individuals declining participation in lung cancer screening: a mixed methods analysis of the UK lung Cancer screening (UKLS) trial. BMJ Open. 2015:5:e008254.

18. van den Bergh KAM, Essink-Bot ML, van Klaveren RJ, de Koning HJ. Informed participation in a randomised controlled trial of computed tomography screening for lung cancer. Eur Respir J. 2009:34:711-20.

19. Carter-Harris L, Pham Ceppa D, Hanna N, Rawl SM. Lung cancer screening: what do long-term smokers know and believe? Health Expect. 2015;20:59-68.

20. Hewitson P, Ward AM, Heneghan C, Halloran SP, Mant D. Primary care endorsement letter and a patient leaflet to improve participation in colorectal cancer screening: results of a factorial randomised trial. $\mathrm{Br}$ J Cancer. 2011;105:475-80.

21. Bevan R, Rubin G, Sofianopoulou E, Patnick J, Rees CJ. Implementing a national flexible sigmoidoscopy screening program: results of the English early pilot. Endoscopy. 2015;47:225-31.

22. TNS. TNS CAPI Omnibus. 2006. http://www.tnsglobal.com/directory/service/ omnibus-united-kingdom. Accessed 13 Sept 2016.

23. Central Statistics Office. Small area population statistics. $2011 \mathrm{http} / / / c e n s u s$. cso.ie/sapmap/. Accessed 13 Sept 2016.

24. Wardle J, Williamson S, McCaffery K, Sutton S, Taylor T, Edwards R, Atkin W. Increasing attendance at colorectal cancer screening: testing the efficacy of a mailed, psychoeducational intervention in a community sample of older adults. Health Psychol. 2003:22:99-105.

25. Simon AE, Forbes $L L$, Boniface $D$, Warburton $F$, Brain KE, Dessaix A, Donnelly M, Haynes K, Hvidberg L, Lagerlund M, Petermann L, Tishelman C, Vedsted P, Vigmostad MN, Wardle J, Ramirez AJ. An international measure of awareness and beliefs about cancer: development and testing of the ABC. BMJ Open. 2012;2:e001758. 
26. Marlow LAV, Wardle J. Development of a scale to assess cancer stigma in the non-patient population. BMC Cancer. 2014;14:285.

27. Lerman C. Psychological and behavioral implications of abnormal mammograms. Ann Intern Med. 1991:114:657.

28. Lerman C, Kash K, Stefanek M. Younger women at increased risk for breast cancer: perceived risk, psychological well-being, and surveillance behavior. J Natl Cancer Inst Monogr. 1994;16:171-6.

29. Kotz D, Brown J, West R. Predictive validity of the motivation to stop scale (MTSS): a single-item measure of motivation to stop smoking. Drug Alcohol Depend. 2013;128:15-9.

30. Sheeran P. Intention — behavior relations: a conceptual and empirical review. Eur Rev Soc Psychol. 2002;12:1-36.

31. Mazieres J, Pujol J, Kalampalikis N, Bouvry D, Quoix E, Filleron T, Targowla N, Jodelet D, Milia J, Milleron B. Perception of lung cancer among the general population and comparison with other cancers. J Thorac Oncol. 2015;10:420-5.

32. Vrinten C, Waller J, von Wagner C, Wardle J. Cancer fear: facilitator and deterrent to participation in colorectal Cancer screening. Cancer Epidemiol Biomark Prev. 2015;24:400-5.

33. Friedemann Smith C, Whitaker KL, Winstanley K, Wardle J. Smokers are less likely than non-smokers to seek help for a lung cancer 'alarm' symptom. Thorax. 2016;71:659-61.

34. Quaife SL, McEwen A, Janes SM, Wardle J. Smoking is associated with pessimistic and avoidant beliefs about cancer: results from the international Cancer benchmarking partnership. Br J Cancer. 2015;112:1799-804.

35. Zeliadt SB, Heffner JL, Sayre G, Klein DE, Simons C, Williams J, Reinke LF, Au $\mathrm{DH}$. Attitudes and perceptions about smoking cessation in the context of lung Cancer screening. JAMA Intern Med. 2015;175:1530-7.

36. Office for National Statistics. Chapter 1 - Smoking (General Lifestyle Survey Overview - a report on the 2011 General Lifestyle Survey). 2013. http:// www.ons.gov.uk/ons/dcp171776_302558.pdf (accessed: 06/01/2015). Accessed 13 Sept 2016.

37. Grundy E, Holt G. The socioeconomic status of older adults: how should we measure it in studies of health inequalities? J Epidemiol Community Heal. 2001;55:895-904

\section{Ready to submit your research? Choose BMC and benefit from:}

- fast, convenient online submission

- thorough peer review by experienced researchers in your field

- rapid publication on acceptance

- support for research data, including large and complex data types

- gold Open Access which fosters wider collaboration and increased citations

- maximum visibility for your research: over $100 \mathrm{M}$ website views per year 